\title{
Chain Length Effects on Crystal Formation in Vinylidene Fluoride Oligomers
}

\author{
Herman, Susumu Umemoto, Takeshi Kikutani, and Norimasa Okui ${ }^{\dagger}$ \\ Department of Organic and Polymeric Materials, Tokyo Institute of Technology, \\ Ookayama, Meguro-ku, Tokyo 152-8552, Japan
}

(Received February 16, 1998)

\begin{abstract}
Crystal modifications in vinylidene fluoride (VDF) oligomers, such as $\alpha, \beta$, and $\gamma$ forms, were studied as a function of the molecular chain length. VDF oligomers were prepared by a telomerization method and the oligomers were fractionated by vacuum vapor deposition. The fractionated oligomers were crystallized from the melt. The crystal forms in VDF oligomers were characterized by IR, X-ray, and DSC methods. The $\beta$ form was found in the degree of polymerization $(N)$ less than 10, the $\alpha$ form consisted of $N$ ranging from 10 to 16 and the $\gamma$ form was observed in $N$ above 16 . The effect of molecular chain length on the crystal forms in VDF oligomers could be associated with change in the conformational energy accompanying the steric hindrance along the molecular chain for the $\beta$ form and differences in the crystallization behavior from the melt for the $\alpha$ and $\gamma$ forms.

KEY WORDS Vinylidene Fluoride / Poly(vinylidene fluoride) / Oligomer / Fractionation / Crystal Form / Chain Length / Vapor Deposition /
\end{abstract}

The crystal forms of poly(vinylidene fluoride) (PVDF) have been classified into three forms, such as $\alpha, \beta$, and $\gamma .{ }^{1}$ In general, the $\alpha$ form can be obtained by crystallizing PVDF from the melt or by casting it from acetone solution. The $\beta$ form can be obtained by drawing and poling PVDF film or by quenching the film from the molten state. The $\gamma$ form can be prepared by annealing the film at a relatively high temperature.

PVDF is thermally decomposed in a vacuum system when the polymer is heated above $300^{\circ} \mathrm{C}^{2,3}$ However, low molecular weight fractions (oligomer) in PVDF can be evaporated without thermal decomposition at temperatures below $300^{\circ} \mathrm{C}^{2,3}$ The degree of polymerization (molecular weight) of vinylidene fluoride(VDF) oligomer extracted by vacuum vapor deposition below $300^{\circ} \mathrm{C}$ is about $20{ }^{2}$ The chain ends of the oligomer are terminated with $-\mathrm{CH}_{3}$ and $-\mathrm{CF}_{2} \mathrm{H}$ and/or with the fragments of initiator. When this oligomer is crystallized from the melt or cast from acetone solution, the $\alpha$ form is observed. Oligomers terminated with $-\mathrm{Cl}$ and $-\mathrm{CCl}_{3}$ at the chain ends can be prepared by telomerization of VDF monomer in the presence of $\mathrm{CCl}_{4}$. These VDF oligomers show $\alpha, \beta$, and $\gamma$ depending on the degree of polymerization and crystallization conditions. ${ }^{4}$ The $\alpha$ form is observed for oligomers with polymerization of about 20 , when crystallized by casting from acetone solution. However, the $\gamma$ form is found when crystallized from the melt. The $\beta$ form with the mixture of the $\gamma$ form is observed for oligomers with polymerization of about 9 , when crystallized from the melt and cast from acetone solution. The pure $\beta$ form is found when the oligomer is deposited on the substrate from the crucible kept at $120^{\circ} \mathrm{C}$.

In this study, the oligomers prepared by telomerization are fractionated by a vacuum deposition method and the effects of molecular chain length on the crystal formation in the fractionated VDF oligomers are studied.

\footnotetext{
$\dagger^{\dagger}$ To whom all correspondence should be addressed.
}

\section{EXPERIMENTAL}

Two VDF oligomers (A and B) were used as starting materials. Oligomers of A and B were kindly supplied from Kureha Co., Ltd. where VDF monomers were telomerized by a suspension polymerization method terminated with $-\mathrm{Cl}$ and $-\mathrm{CCl}_{3}$ at their chain ends. The degrees of polymerization for oligomers $\mathrm{A}$ and $\mathrm{B}$ are about 9 and 20 , respectively, as determined by elemental analysis, NMR and GPC. ${ }^{4}$ Oligomer A exhibited two molecular weight distributions whereas oligomer B showed a single molecular distribution. The chemical structures, the head-to-tail perfection and the degree of polymerization are summarized in Table I.

The apparatus for vapor deposition was a EBH-6 vacuum coating unit (ULVAC Co., Ltd.). Oligomers A and $\mathrm{B}$, prepared by telomerization, were further fractionated by vacuum deposition, since the low molecular weight fractions were more easily separated by vaporization than the high molecular weight fractions.

IR spectra of the samples were recorded by JASCO Micro FTIR 100T. X-Ray diffraction patterns were recorded with a conventional $\theta-2 \theta$ diffractometer using $\mathrm{Ni}$ filtered $\mathrm{Cu}-K_{\alpha} \mathrm{X}$-rays (Rigaku Rad-B). Melting and crystallization temperatures for the samples were recorded on a Shimadzu T40 differential scanning calorimeter (DSC) at heating and cooling rates of $10^{\circ} \mathrm{C} \mathrm{min}^{-1}$.

\section{RESULTS AND DISCUSSION}

Figure 1 shows IR spectra for oligomers of A and B casting from acetone solution onto a silicon wafer. Oligomer B shows a typical $\alpha$ form in IR spectra,

Table I. Chemical structures, percentage of head-to-tail monomer sequences (H-T) and degree of polymerization $(N)$ for PVDF oligomers determined by NMR

\begin{tabular}{cccr}
\hline Sample & Chemical structure & $\mathrm{H}-\mathrm{T} / \%$ & $N$ \\
\hline $\mathrm{A}$ & $\mathrm{CCl}_{3}-\left(\mathrm{CH}_{2} \mathrm{CF}_{2}\right)_{n}-\mathrm{Cl}$ & 96.0 & 9 \\
$\mathrm{~B}$ & $\mathrm{CCl}_{3}-\left(\mathrm{CH}_{2} \mathrm{CF}_{2}\right)_{n}-\mathrm{Cl}$ & 93.5 & 20 \\
\hline
\end{tabular}




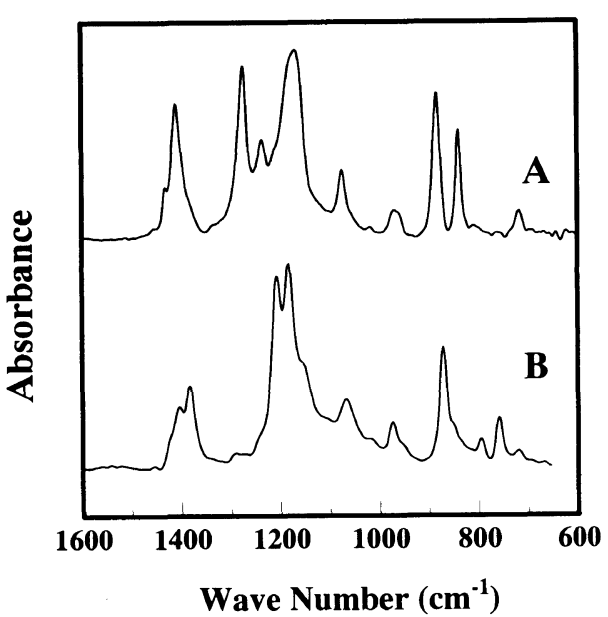

Figure 1. IR spectra of two oligomers A and B cast from acetone solution onto the silicon wafer substrate.

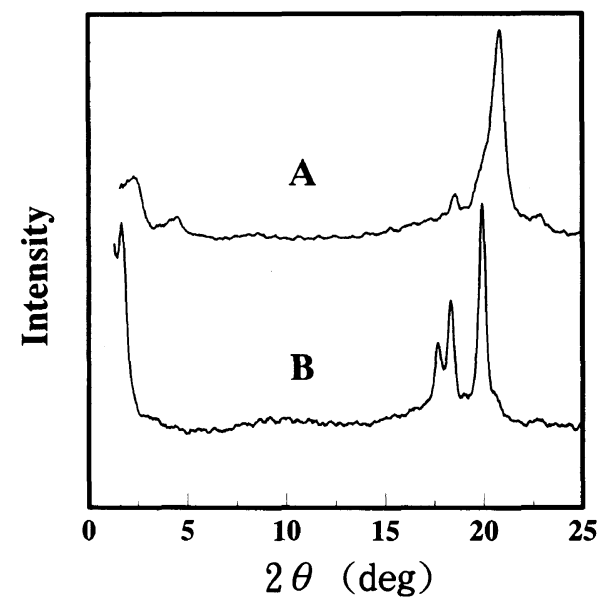

Figure 2. X-ray diffraction patterns of two oligomers A and B cast from acetone solution onto the silicon wafer substrate.

exhibiting the characteristic absorption bands at $1212 \mathrm{~cm}^{-1}$ and $1185 \mathrm{~cm}^{-1}$. In general, the $\alpha$ form can be obtained when PVDF is cast from acetone solution. ${ }^{1}$ The cast-film of oligomer A shows a mixture of the $\beta$ and $\gamma$ forms exhibiting the characteristic bands at $1278 \mathrm{~cm}^{-1}$ for the $\beta$ form and at $1236 \mathrm{~cm}^{-1}$ for the $\gamma$ form and with a small amount of the $\alpha$ form indicated by the small shoulder peak at around $1200 \mathrm{~cm}^{-1}$. However, the $\beta$ form is a major component in the cast-film of oligomer A. Figure 2 shows X-ray diffraction patterns for oligomers $\mathrm{A}$ and $\mathrm{B}$ cast from acetone solution. The X-ray diffraction pattern of oligomer $\mathrm{B}$ shows three sharp peaks at $2 \theta=17.7^{\circ}, 18.3^{\circ}$, and $19.9^{\circ}$ corresponding to the (100), (020), and (110) reflections, respectively, for the $\alpha$ form, and at one at $2 \theta=1.76^{\circ}$ associated with the long spacing of the $\alpha$ form crystals. The degree of polymerization calculated from the long spacing is about 21.7, which coincides with 20 obtained by NMR method. The peaks at $2 \theta=21^{\circ}$ corresponding to the (200) and (110) reflections for the $\beta$ form, and one at $2 \theta=18^{\circ}$ corresponding to the $(020)$ for the $\gamma$ form are found in Figure 2 for oligomer $\mathrm{A}$. The other two peaks are found at $2 \theta=2.3^{\circ}$ and $4.2^{\circ}$, corresponding to spacings of 3.84 and $2.1 \mathrm{~nm}$, respectively. The degrees of polymerization calculated from these spacing are 8.1 and 15.

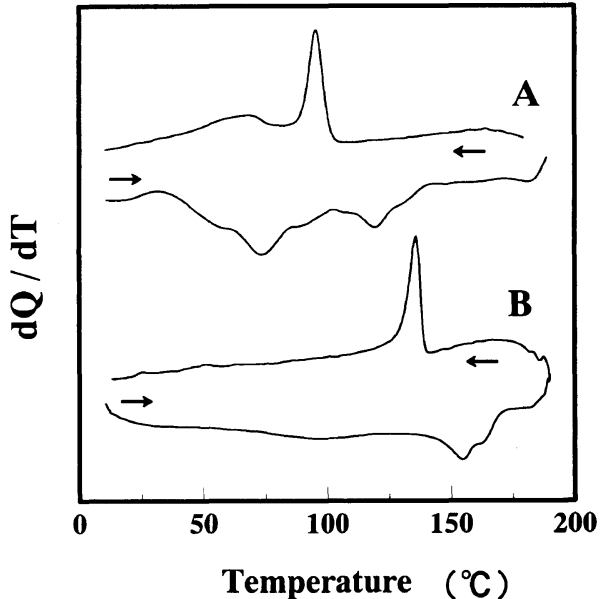

Figure 3. DSC curves of two oligomers A and B. Arrows indicate directions of heating and cooling.

Figure 3 shows DSC melting and crystallization thermograms recorded on heating and cooling process for oligomers $\mathrm{A}$ and $\mathrm{B}$. Oligomer $\mathrm{A}$ exhibits two melting peaks at about $80^{\circ} \mathrm{C}$ and $117^{\circ} \mathrm{C}$ with a couple of shoulder peaks and two crystallization peaks at $102^{\circ} \mathrm{C}$ and $67^{\circ} \mathrm{C}$. According to the results of GPC, ${ }^{2,3}$ oligomer A showed the double molecular weight distributions. These two molecular weight fractions are crystallized independently at $102^{\circ} \mathrm{C}$ and $67^{\circ} \mathrm{C}$. The crystallization peak at $67^{\circ} \mathrm{C}$ is very broad compared to the crystallization peak at $102^{\circ} \mathrm{C}$. The melting peak at $80^{\circ} \mathrm{C}$ is also very broad with a couple of shoulder peaks. These data indicate that oligomer A consists of many low molecular weight fractions. In fact, the external appearance of sample $\mathrm{A}$ is a wax-like material while sample B shows a powder-like material. According to the above IR, X-ray, and DSC data for oligomer A, the lower melting temperatures can be related to the $\beta$ form and the higher melting temperatures can be associated with the mixtures of the $\alpha$ and $\gamma$ forms. There is a single crystallization peak at $136^{\circ} \mathrm{C}$ and a single melting peak at about $155^{\circ} \mathrm{C}$ with a small shoulder peak around $160^{\circ} \mathrm{C}$ for oligomer $\mathrm{B}$, consistent with a single molecular weight distribution of this oligomer.

Figures 4 and 5 show DSC melting and crystallization temperatures for the vapor deposited samples from oligomers A and B, respectively, which were evaporated from a crucible kept at various temperatures indicated in the figure. Lower crucible temperatures yield lower melting and crystallization temperatures for the vapor deposited samples. Single melting and single crystallization temperatures are found for both oligomers deposited at $120^{\circ} \mathrm{C}$. When the crucible temperature is raised to $160^{\circ} \mathrm{C}$ after $2 \mathrm{~h} \mathrm{kept}$ at $120^{\circ} \mathrm{C}$ or increased to $200^{\circ} \mathrm{C}$ after $2 \mathrm{~h}$ kept at $160^{\circ} \mathrm{C}$, two DSC peaks are observed on heating and cooling for oligomer A. Double melting and double crystallization temperatures appear for oligomer $\mathrm{B}$ evaporated at $200^{\circ} \mathrm{C}$ and $250^{\circ} \mathrm{C}$. The melting and crystallization temperatures increase with crucible temperature. Figure 6 shows a relationship between the melting temperature of the evaporated oligomer and the crucible temperature (evaporation temperature). It is clear that lower evaporation temperature yields the lower melting temperature indicating molecular fractionation by vapor deposition. 


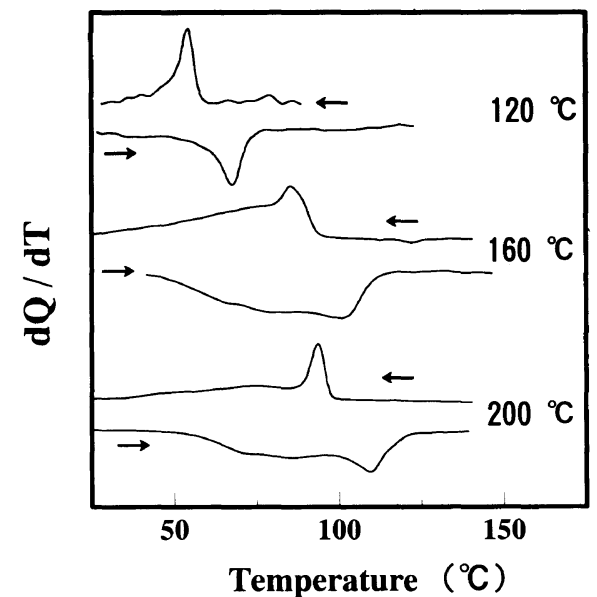

Figure 4. DSC curves of vapor deposited sample for oligomer A from the crucible kept at $120^{\circ} \mathrm{C}, 160^{\circ} \mathrm{C}$, and $200^{\circ} \mathrm{C}$. Arrows indicate directions of heating and cooling.

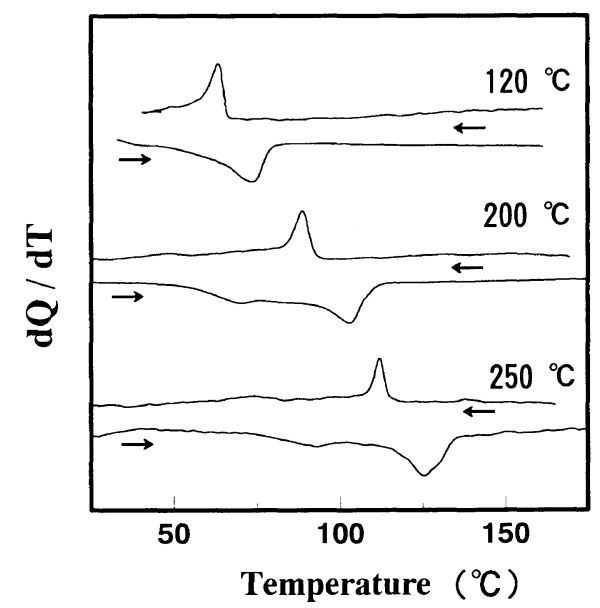

Figure 5. DSC curves of vapor deposited sample for oligomer B from the crucible kept at $120^{\circ} \mathrm{C}, 200^{\circ} \mathrm{C}$, and $250^{\circ} \mathrm{C}$. Arrows indicate directions of heating and cooling.

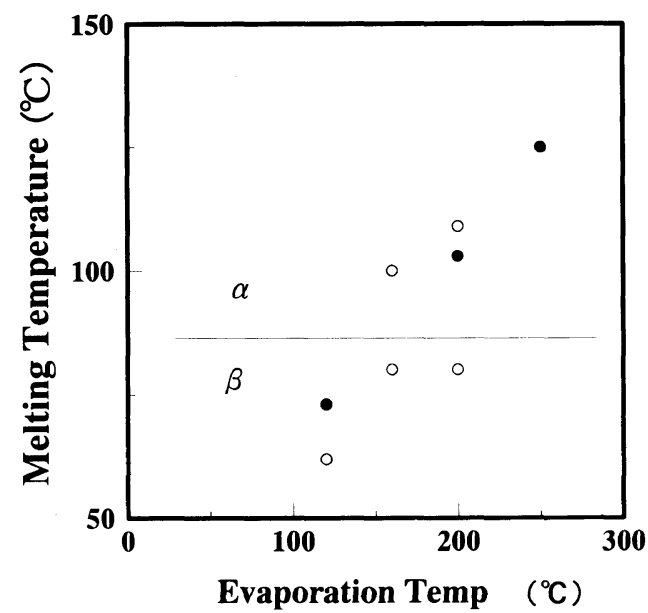

Figure 6. Relationship between melting temperature of deposited samples and evaporation temperature (crucible temperature). $\bigcirc$ and - stand for oligomers A and B, respectively.

Figures 7 and 8 show three typical IR spectra and $\mathrm{X}$-ray diffraction patterns for the deposited samples obtained at different deposition temperatures. The $\beta$ form is obtained for oligomer A evaporated at $120^{\circ} \mathrm{C}$

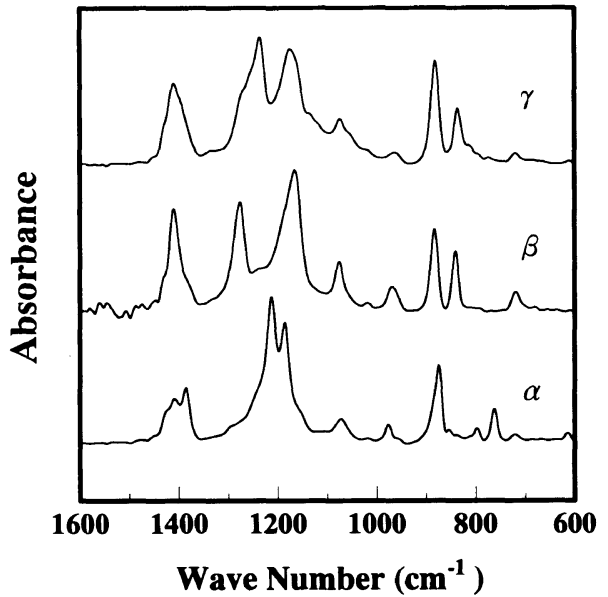

Figure 7. IR spectra of three typical deposited samples. The $\beta$ form is obtained for oligomer A evaporated at $120^{\circ} \mathrm{C}$ and the $\alpha$ form for oligomer B evaporated at $200^{\circ} \mathrm{C}$. The $\gamma$ form is found in residual samples for oligomers $\mathrm{A}$ and $\mathrm{B}$ in the crucible after vapor evaporation at $250^{\circ} \mathrm{C}$.

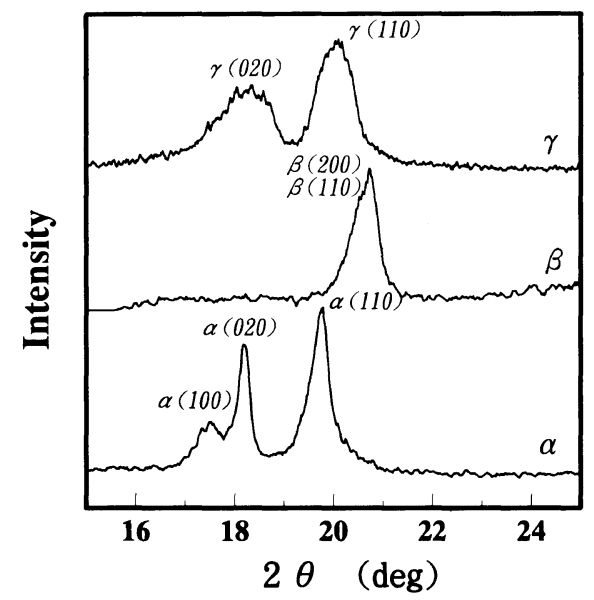

Figure 8. X-Ray diffraction patterns of three typical deposited samples. The $\beta$ form is obtained for oligomer $\mathrm{A}$ evaporated at $120^{\circ} \mathrm{C}$ and the $\alpha$ form for oligomer B evaporated at $200^{\circ} \mathrm{C}$. The $\gamma$ form is found in residual samples for oligomers $\mathrm{A}$ and $\mathrm{B}$ in the crucible after vapor evaporation at $250^{\circ} \mathrm{C}$.

and the $\alpha$ form is obtained for oligomer $\mathrm{B}$ evaporated at $200^{\circ} \mathrm{C}$. The corresponding degree of polymerization for these $\alpha$ and $\beta$ forms are about 12 and 8 , respectively, as evaluated from the small angle X-ray diffraction patterns. The $\gamma$ form is found in the residual samples for oligomers $\mathrm{A}$ and $\mathrm{B}$ in the crucible after vapor evaporation experiments at $250^{\circ} \mathrm{C}$.

Figure 9 shows the relationship between the melting $\left(T_{\mathrm{m}}\right)$ and crystallization $\left(T_{\mathrm{c}}\right)$ temperatures for the deposited samples onto the substrate and residual samples in the crucible. The crystal forms for the fractionated samples (deposited samples on the substrate) crystallized from the melt after deposition experiments are also indicated in Figure 9. A good linear relationship is found between $T_{\mathrm{m}}$ and $T_{\mathrm{c}}$ in spite of the different crystal forms. It is of interest to note that the $\beta$ form is observed in the lower melting (or crystallization) temperature regions, the $\alpha$ form appears in the medium temperature regions, and the $\gamma$ form is found in the higher temperature regions. Here, these crystal forms are associated with the molecular chain length since the melting and crystallization temperatures are related to 


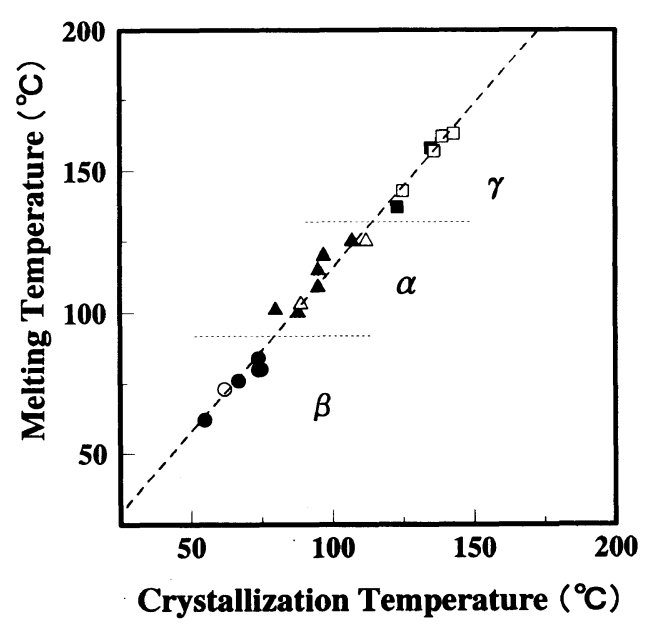

Figure 9. Relationships between melting temperature and crystallization temperature in DSC curves for fractionated and residual samples in the crucible. $\triangle, \bigcirc$, and $\square$, crystal forms $\alpha, \beta$, and $\gamma$, respectively. Solid and open patterns, oligomers $\mathrm{A}$ and $\mathrm{B}$, respectively.

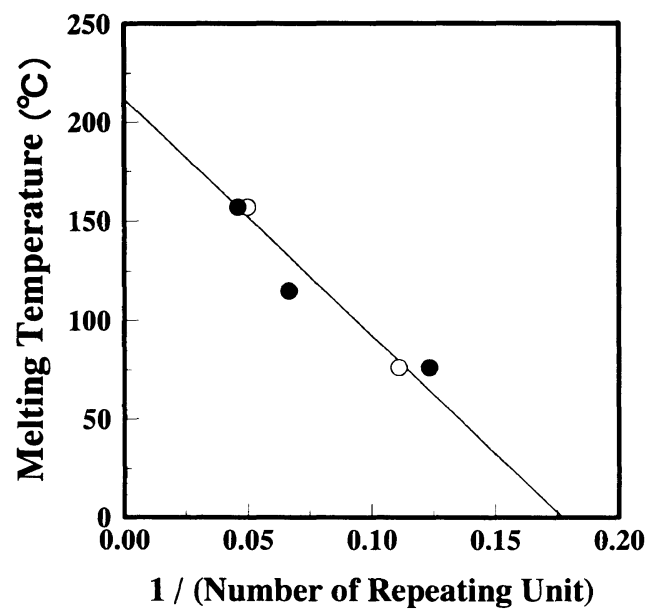

Figure 10. Chain length effects on melting temperature for VDF oligomers. The degree of polymerization $(N)$ was determined by NMR (O) and X-ray long spacing (O)

the molecular chain length in the oligomer. The melting behavior of the deposited oligomer can be classified into two groups (such as $\alpha$ and $\beta$ forms) as a function of evaporation temperature as indicated in Figure 6.

Molecular chain length can be estimated from the following simple equation, ${ }^{5}$

$$
1 / T_{\mathrm{m}}(N)=1 / T_{\mathrm{m}}^{\circ}+K / N
$$

where $T_{\mathrm{m}}(N)$ and $T_{\mathrm{m}}^{\circ}$ are melting temperatures for an extended chain crystal constructed with a number of repeating unit $(N)$ and with an infinite chain length (i.e., an equilibrium crystalline melting temperature for a polymer), respectively. $K$ is a constant. On the basis of the melting temperatures of the characterized oligomers, a good linear relationship is found in Figure 10. The extrapolated melting temperature $T_{\mathrm{m}}^{\circ}$ in Figure 10 was $485.7 \mathrm{~K}$, which coincides with the equilibrium melting temperature of PVDF. ${ }^{6}$ The degrees of polymerization for various fractionated oligomers can be estimated from their melting temperatures according to the results of Figure 10. Figure 11 shows the relationship between the melting temperature and degree of polymerization for the fractionated and residual oligomers in the crucible.

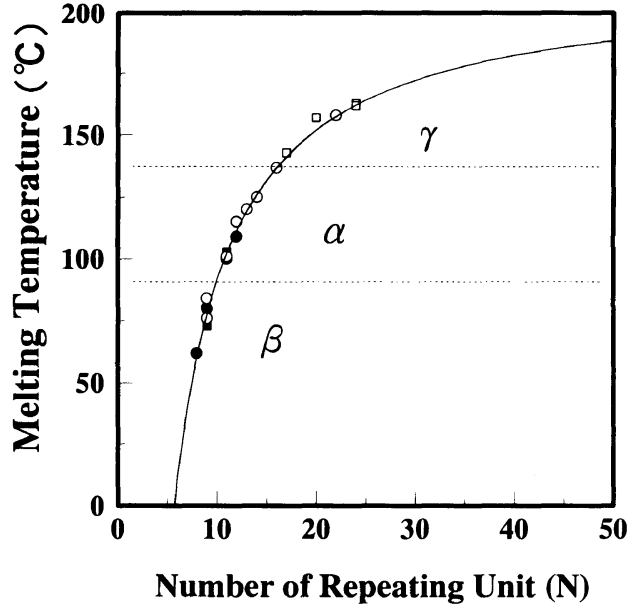

Figure 11. Relationship between melting temperature and number of repeating units for fractionated (solid) and residual samples (open) in the crucible $\bigcirc$ and $\square$, oligomers $A$ and $B$, respectively.

The $\beta$ form is formed with polymerization $(N)$ less than 10 , the $\alpha$ form is formed with $N$ in the range from 10 to 16 and the $\gamma$ form is formed above 16 .

Here, the chain conformation for the $\beta$ form is all-trans conformation. The all-trans arrangement forces the fluorine atoms to come closer together than the sum of their van der Waals radii. The intra-molecular strain associated with the crowding fluorine groups can be reduced by molecular defects such as head to head $(\mathrm{H}-\mathrm{H})$ or tail to tail (T-T) arrangements in the all-trans conformation or by copolymerization with other monomers such as trifluoro-ethylene $\left(\mathrm{VF}_{3}\right)$ or tetrafluoro-ethylene $\left(\mathrm{VF}_{4}\right) .{ }^{1}$ For example, a copolymer containing $7 \% \mathrm{VF}_{4}$ or $17 \% \mathrm{VF}_{3}$ (on a molar basis) can be crystallized to the $\beta$ form. ${ }^{7} \mathrm{H}-\mathrm{H}$ or T-T defect decreases strain in the $\beta$ structure but increases it in the $\alpha$ structure. Above $11 \%$ this defect concentration in PVDF homopolymer, the $\beta$ form becomes energetically most stable. ${ }^{8}$ At such defect concentration, the mean sequence length of all-trans conformation is about 9 repeating units of PVDF. Chain ends also decrease strain in the $\beta$ form. These strain relievers become more prominent in the lower molecular weight oligomer. Thus, polymerization less than 10 yields crystal of the $\beta$ form.

The $\alpha$ and $\gamma$ forms are constructed with the TGTG and $\mathrm{T}_{3} \mathrm{GT}_{3} \mathrm{G}$ molecular conformations, respectively. The $\alpha$ form in PVDF is commonly obtained by crystallization from the melt at moderate or high under-cooling. The $\gamma$ form in PVDF is obtained by crystallization from the melt at relatively high temperatures. The $\alpha$ form can be transformed to the $\gamma$ form by annealing at $160-170^{\circ} \mathrm{C} .{ }^{1}$ Changes in crystallization behavior from the melt and crystalline transformation from the $\alpha$ to $\gamma$ form are strongly related to the temperature dependent crystal growth rate. Temperature dependence on the crystallization rates for the $\alpha$ and $\gamma$ forms shows a crossover point at a given crystallization temperature. The crystallization rate of the $\alpha$ form is faster than that of the $\gamma$ form in the lower crystallization temperature ranges or vice versa at high temperatures in PVDF. VDF oligomers manifest similar crystallization behavior or distinctive crystallization behavior in $\alpha$ and $\gamma$ formation. In this study, the oligomers are crystallized from the melt at a 
cooling rate of $10^{\circ} \mathrm{Cmin}^{-1}$. The large polymerization reflects high melting temperature for the oligomer. The high molecular weight fractions can be crystallized at relatively high temperature through cooling from the melt. Therefore, the fractions of low polymerization in the range of $10-16$ are crystallized to the $\alpha$ form and fractions above 16 are crystallized to the $\gamma$ form.

The effects of molecular chain length on the crystal forms in PVDF oligomers are associated with changes in the conformational energy accompanying steric hindrance along the molecular chain for the $\beta$ form and with differences in crystallization behavior from the melt for the $\alpha$ and $\gamma$ forms.

Acknowledgment. The authors are grateful to Mr. N. Bannai of Kureha Chemical Industry Co., Ltd. for preparing the oligomers.

\section{REFERENCES}

1. A. J. Lovinger, in "Developments in Crystalline Polymers-1," D. C. Bassett, Ed., Applied Science Publishers, London, 1982, Chapter 5, p 201

2. A. Takeno, N. Okui, T. Kitoh, M. Muraoka, S. Umemoto, and T. Sakai, Thin Solid Films, 202, 205 (1991).

3. A. Takeno, N. Okui, T. Hiruma, T. Kitoh, M. Muraoka, S. Umemoto, and T.Sakai, Koubunshi Ronbunshu, 48, 399 (1991).

4. Herman, T. Uno, A. Kubono, S. Umemoto, T. Kikutani, and N. Okui, Polymer, 38, 1677 (1997).

5. P. J. Flory, "Principles of Polymer Chemistry," Cornel University Press, Ithaca, N.Y., 1953, Chapter 8, p 570.

6. B. Wunderlich, "Macromolecular Physics," Vol. 3, Crystal Melting, Academic Press, New York, N.Y., 1980, Chapter 8, p 50.

7. J. B. Lando and W. W. Doll, J. Macromol. Sci.-Phys., B2, 2051 (1968).

8. B. L. Farmer, A. J. Hopfinger, and J. B. Lando, J. Appl. Phys., 43, 4293 (1972) 